\title{
Factors Concerning the Dynamics of Footbridges and Methods for Improving Pedestrians' Comfort
}

\author{
Suciu Mircea, Drăgan Delia and Nerișanu Raluca
}

\begin{abstract}
Pedestrian bridges are constructions that are part of the category Bridges, having the particularity that due to much lower loading as compared to that of road or railway bridges, their decks are much slenderer, and can be included in the category of light structures. In this paper several aspects regarding the dynamic behavior of the footbridge structures under the traffic actions correlated with the pedestrians' comfort are presented. The comfort criteria depend of the frequencies and accelerations of the structure and have to be situated between certain limits. If the frequencies and accelerations of the structure are in the critical domains, measures to modify them have to be taken, some of them being presented in this paper as they are the most usually used.
\end{abstract}

Keywords - critical frequency and acceleration, dynamic parameters modification, dynamic response, footbridges, traffic comfort.

\section{INTRODUCTION}

This paper presents aspects related to the dynamic behaviour of footbridge structures under pedestrian traffic, without taking into account the dynamic behaviour given by the wind action.

The paper briefly presents the methodology for assessing the pedestrian traffic comfort on footbridges, correlated with the structure frequency and its acceleration, evaluated from the permanent loads or from some dynamic load models.

The maximal comfort criterion for pedestrians requires zero vibrations, which would lead to a heavy structure or would require vibration damping systems.

\section{DYNAMICS OF THE STRUCTURE AND THE PEDESTRIANS' TRAFFIC COMFORT}

Dynamic parameters

The critical damping ratio " $\xi "$ is defined:

$\xi=\frac{\mathrm{c}}{2 \sqrt{\mathrm{k} \cdot \mathrm{m}}}($ dimensionless $) ; 0<\xi<1$ 
The dynamic amplification factor $\mathrm{A}(\Omega)$ :

$\mathrm{A}(\Omega)=\frac{1}{\sqrt{\left(1-\Omega^{2}\right)+4 \xi^{2} \Omega^{2}}} ; \Omega=\frac{\omega}{\omega_{0}}-$ the reduced (relative) pulsation

The resonance pulsation of the structure:

$\omega_{\mathrm{R}}=\omega_{0} \sqrt{1-2 \xi^{2}}$

Technical literature (e.g. [7]) recommends critical damping factor values according to Table 1.

Table 1. Critical damping ratio.

\begin{tabular}{|l|c|c|}
\hline \multirow{2}{*}{\multicolumn{1}{c|}{ Type of deck }} & \multicolumn{2}{c|}{ Critical damping ratio } \\
\cline { 2 - 3 } & Minimum value & Average value \\
\hline Reinforced concrete & $0.8 \%$ & $1.3 \%$ \\
\hline Prestressed concrete & $0.5 \%$ & $1.0 \%$ \\
\hline Metal & $0.2 \%$ & $0.4 \%$ \\
\hline Composite & $0.3 \%$ & $0.6 \%$ \\
\hline Timber & $1.5 \%$ & $3.0 \%$ \\
\hline
\end{tabular}

\section{Dynamic loading cases}

Depending on the class of the walkway and the range in which the natural frequencies fall, the dynamic calculation for three loading cases is required: Case 1 - sparse and dense crowd; Case 2 - very dense crowd and Case 3 - evenly distributed crowd.

Case 1 shall be considered for classes III and II footbridges. The density $d$ of the pedestrian crowd shall be considered as follows: $\mathrm{d}=0.5$ pedestrian $/ \mathrm{m}^{2}$ - Class III; $\mathrm{d}=0.8$ pedestrian $/ \mathrm{m}^{2}-$ Class II.

The number of equivalent pedestrians, respectively the number of pedestrians who, being all at the same frequency and in phase, would produce the same effects as random pedestrians, in frequency and in phase, is $10.8 \cdot \sqrt{\mathrm{N} \cdot \xi}$.

The load that is to be taken into account is modified by a factor $\Psi$ which makes allowance for the fact that the risk of resonance in a footbridge becomes less likely the further way from the range $1.7 \mathrm{~Hz}-2.1 \mathrm{~Hz}$ for vertical accelerations, and $0.5 \mathrm{~Hz}-1.1 \mathrm{~Hz}$ for horizontal accelerations, Figure 1.

a)

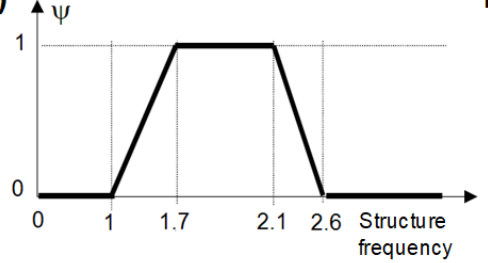

b)

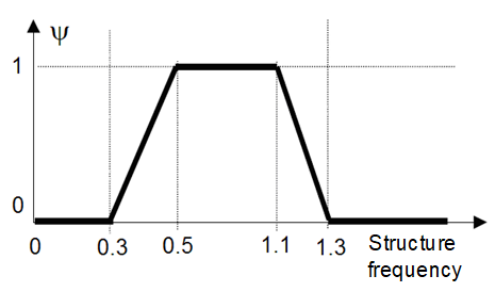

Fig. 1. Factor $\Psi$ in the case of walking:

a) vertical and longitudinal vibrations; b) lateral vibrations 
Table 2 summarizes the load to be applied per unit of area for each vibration direction.

Table 2. Load applied per unit of area, Fs [N/m2]

\begin{tabular}{|l|c|}
\hline \multicolumn{1}{|c|}{ Direction } & Load per $\mathbf{~ m}^{2}$ \\
\hline Vertical $(\mathrm{v})$ & $\mathrm{d} \times(280 \mathrm{~N}) \times \cos \left(2 \pi \mathrm{f}_{\mathrm{v}} \mathrm{t}\right) \times 10.8 \sqrt{\xi / \mathrm{n}} \times \Psi$ \\
\hline Longitudinal $(\mathrm{l})$ & $\mathrm{d} \times(140 \mathrm{~N}) \times \cos \left(2 \pi \mathrm{f}_{\ell} \mathrm{t}\right) \times 10.8 \sqrt{\xi / \mathrm{n}} \times \Psi$ \\
\hline Transversal $(\mathrm{t})$ & $\mathrm{d} \times(35 \mathrm{~N}) \times \cos \left(2 \pi \mathrm{f}_{\mathrm{t}} \mathrm{t}\right) \times 10.8 \sqrt{\xi / \mathrm{n}} \times \Psi$ \\
\hline
\end{tabular}

Case 2 for very dense crowd is only to be taken into account for Class I footbridges. The pedestrian crowd density to be considered is set at 1 pedestrian $/ \mathrm{m}^{2}$, assumed to be uniformly distributed over an area S.

The number of equivalent pedestrians is $1.85 \cdot \sqrt{\mathrm{n}}$.

Table 3 gives the load to be applied per unit of area for each vibration direction.

Table 3. Load applied per unit of area, Fs [N/m2].

\begin{tabular}{|l|c|}
\hline \multicolumn{1}{|c|}{ Direction } & Load per $\mathbf{~ m}^{2}$ \\
\hline Vertical $(\mathrm{v})$ & $1.0 \times(280 \mathrm{~N}) \times \cos \left(2 \pi \mathrm{f}_{\mathrm{v}} \mathrm{t}\right) \times 1.85 \sqrt{1 / \mathrm{n}} \times \Psi$ \\
\hline Longitudinal $(\mathrm{l})$ & $1.0 \times(140 \mathrm{~N}) \times \cos \left(2 \pi \mathrm{f}_{\ell} \mathrm{t}\right) \times 1.85 \sqrt{1 / \mathrm{n}} \times \Psi$ \\
\hline Transversal $(\mathrm{t})$ & $1.0 \times(35 \mathrm{~N}) \times \cos \left(2 \pi \mathrm{f}_{\mathrm{t}} \mathrm{t}\right) \times 1.85 \sqrt{1 / \mathrm{n}} \times \Psi$ \\
\hline
\end{tabular}

Case 3 is like cases 1 and 2, but the secondary harmonic is considered with a double frequency compared to the first harmonic. The density of the pedestrian crowd to be considered is 0.8 pedestrians $/ \mathrm{m}^{2}$ for Class II, and 1.0 for Class I and the factor $\psi$ can be obtained from Figure 2.
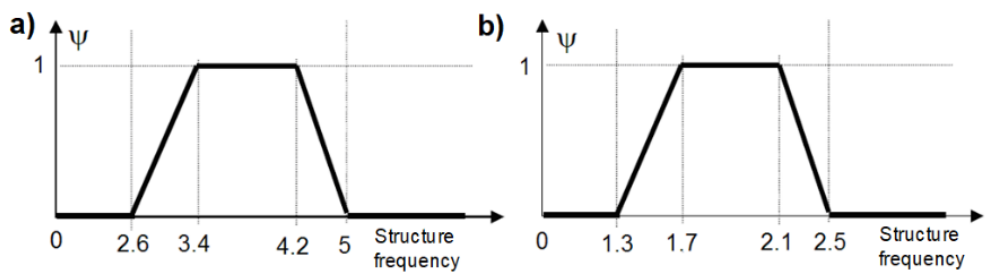

Fig. 2. Factor $\Psi$ in the case of walking: a) vertical vibrations; b) lateral vibrations

\section{THE DYNAMICS OF FOOTBRIDGES AND THE TRAFFIC COMFORT CRITERION}

\section{Classes and comfort level of footbridges}

There are four Traffic Classes for footbridges, depending on the size of the estimated traffic, Table 4, [6], [7]:

Table 4. Classes of footbridges depending on traffic characteristics.

\begin{tabular}{|c|l|}
\hline Class & \multicolumn{1}{|c|}{ Traffic characteristics } \\
\hline I & urban footbridges with high pedestrian density, subjected to very heavy traffic \\
\hline II & urban footbridges, occasionally loaded on the entire surface \\
\hline III & footbridges for normal use; occasionally crossed by large groups of pedestrians \\
\hline IV & footbridges occasionally crossed \\
\hline
\end{tabular}


The footbridge beneficiary can establish one of the three levels of comfort for the bridge users shown in Table 5 .

Table 5. Comfort levels.

\begin{tabular}{|l|l|}
\hline \multicolumn{1}{|c|}{ Comfort levels } & \multicolumn{1}{c|}{ Characteristics } \\
\hline Maximum comfort & structural acceleration is virtually imperceptible \\
\hline Medium comfort & acceleration is slightly perceptible \\
\hline Minimum comfort & acceleration is perceived by the users, but at a tolerable level \\
\hline
\end{tabular}

The load given by the pedestrian walking or running is equivalent to a timeconcentrated force.

Experimental measurements have shown that the load has a periodic character and is characterized by frequency and the number of steps per second.

The estimated frequency values are given in Table 6, [7].

Table 6. Frequencies induced by pedestrians

\begin{tabular}{|l|l|c|}
\hline & \multicolumn{1}{|c|}{ Walking characteristics } & Frequency $[\mathrm{Hz}]$ \\
\hline Walking & continuous contact with the surface & $1.6 \ldots 2.4$ \\
\hline Running & discontinuous contact & $2.0 \ldots 3.5$ \\
\hline
\end{tabular}

Conventionally, for walking, the frequency can be described by a Gaussian curve with an average value of $2 \mathrm{~Hz}$ and a standard deviation of $0.20 \mathrm{~Hz}$.

\section{Parameters that influence the design}

\section{Range of acceleration values associated with comfort level}

Regarding the critical accelerations $-\mathrm{a}_{\text {crit }}$, these are determined in relation to the natural frequency of the structure and differ according to the technical reference material.

According to EN 1990-EC 0 - Annex A2, [8], the maximum recommended accelerations are as follows: $0.7 \mathrm{~m} / \mathrm{s}^{2}-$ vertical vibrations; $0.2 \mathrm{~m} / \mathrm{s}^{2}$ - horizontal vibrations; $0.4 \mathrm{~m} / \mathrm{s}^{2}$ - for exceptional situations (agglomerations).

Verification of the comfort criterion should be performed if the fundamental frequency of the structure is less than the values: $5 \mathrm{~Hz}$ - for vertical vibrations; $2.5 \mathrm{~Hz}$ - for horizontal (lateral) vibrations and torsional vibrations.

The methodology presented in papers [1], [6], [7] aims at avoiding the resonance phenomenon that can occur in the case of very light bridge structures.

Four conventional areas for vertical and horizontal accelerations are defined, Figure 3 , in ascending order, corresponding to maximum, medium and minimum comfort levels, where field 4 corresponds to inadmissible acceleration values, [6], [7].

\begin{tabular}{|c|c|c|c|c|}
\hline RANGES & 0. & 1 & acc. [m/s $\left.{ }^{2}\right]$ & 2.5 \\
\hline 1 & MAX. & & & \\
\hline 2 & & MEAN & & \\
\hline 3 & & & MIN. & \\
\hline 4 & & & & \\
\hline
\end{tabular}

\begin{tabular}{|c|c|c|c|c|c|}
\hline RANGES & $\begin{array}{ll}0 & 0.1\end{array}$ & 0.15 & 0.3 & acc. $\left[\mathrm{m} / \mathrm{s}^{2}\right]$ & 0.8 \\
\hline 1 & MAX. & & & & \\
\hline 2 & & MEAN & & & \\
\hline 3 & & & & MIN. & \\
\hline 4 & & & & & \\
\hline
\end{tabular}

Fig. 3. Acceleration areas and comfort levels 


\section{Range of frequency values associated with comfort level}

For footbridges that fall into classes I, II and III, it is necessary to calculate the natural vibration frequency of the structure. These frequencies are evaluated for the three directions: vertical, horizontal transverse and horizontal longitudinal

Frequencies are determined for two mass assumptions of the system: unloaded footbridge; the bridge loaded on the walkway with $700 \mathrm{~N} / \mathrm{m}^{2}$.

Table 7 gives the risk frequency domains for vertical vibrations, specified in various technical papers, norms and regulations, [1], [7].

Table 7. Risk frequencies.

\begin{tabular}{|l|c|}
\hline \multicolumn{1}{|c|}{ Norm, regulations } & Frequency $[\mathrm{Hz}\}$ \\
\hline Eurocode 2 & $1.6-2.4$ \\
\hline Eurocode 5 & $0-5$ \\
\hline Eurocode 0 & $<5$ \\
\hline BS 5400 & $<5$ \\
\hline Japan regulation & $1.5-2.3$ \\
\hline
\end{tabular}

Depending on the area in which these frequencies are located, the risk of resonance caused by pedestrian traffic can be assessed, and the load cases for dynamic calculation can be determined and the comfort criterion can be checked as well.

Vertical and horizontal frequencies may fall into four areas of the resonance risk, Figure 4, [1], [7], where: Domain 1: maximum resonance risk; Domain 2: average resonance risk; Domain 3: low resonance risk; Domain 4: negligible resonance risk.

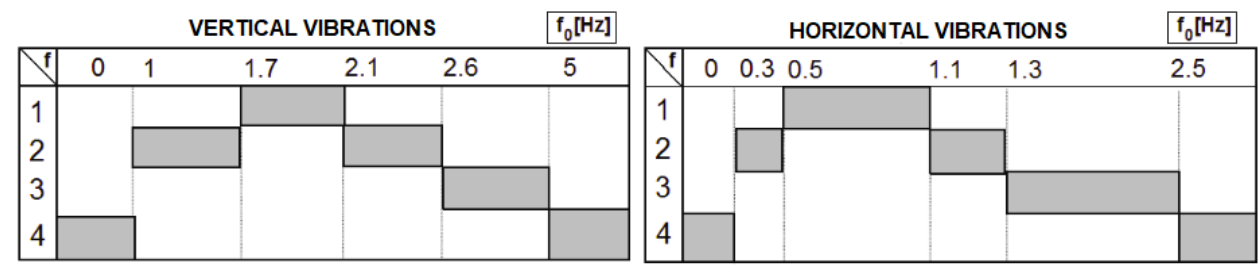

Fig. 4. Frequency and risk areas

\section{IMPROVING DYNAMIC BEHAVIOUR}

\subsection{Structural improvement}

If the limit acceleration criterion is not met, measures to improve dynamic behavior should be considered.

For a footbridge in the design phase, the logical course of action is to change the natural vibration frequency so that it is not in the resonance risk area in relation to the excitement generated by pedestrian walking. This generally implies an increase in the damping factor of the structure.

Figure 5 shows the oscillation modes of a deck resulting from the decomposition of the general oscillation into simple oscillations. Thus, it is observed that the deck oscillations consist of the following simple types [2]: vertical oscillations of the main 
beams (a); vertical oscillations of the main beams in antiphase (b); lateral oscillations of horizontal braces (c); lateral oscillations in antiphase (d); oscillation of the upper flanges in the antiphase (e); oscillation from the torsion (f).

a)

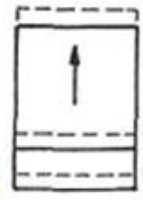

b)

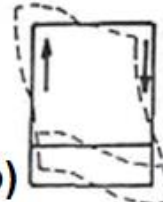

c

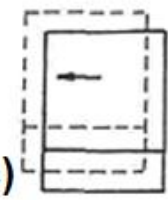

d)

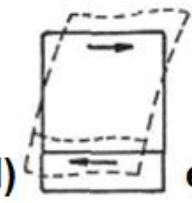

e)

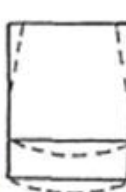

f)

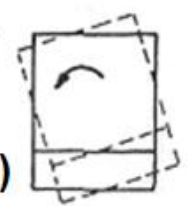

Fig. 5. Decks' oscillations

Changing the natural frequency of the structure in the design phase

When the frequency of vibration Mode 1 is low but in the risk area and the frequency of mode 2 is high enough, it may be advantageous to reduce the mode 1 frequency to lower below the risk threshold and the mode 2 frequency to remain in the higher risk area.

Reducing vertical vibrations

In Figure 6 some of these constructive solutions are presented, [2].
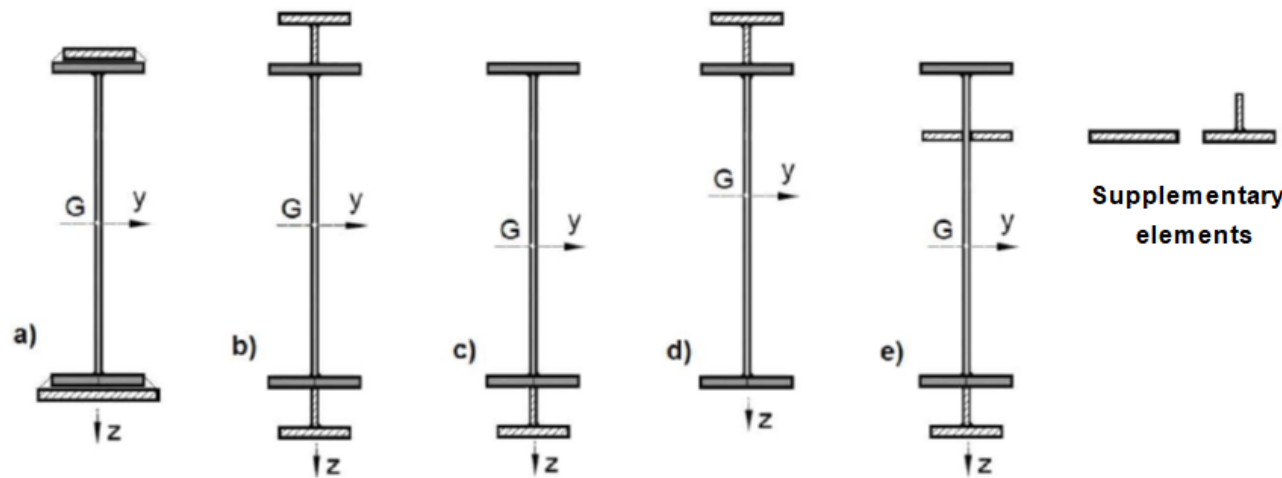

elements

Fig. 6. Main welded girders strengthening

In the case of truss footbridges to improve the dynamic parameters in the vertical plane, the solutions of increasing the girder depths can be also viable, Figure 7.
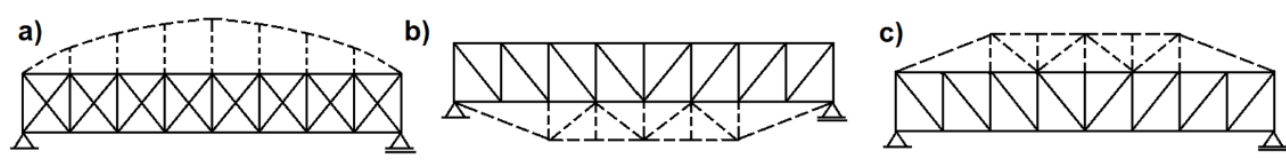

Fig. 7. Truss footbridge consolidation

\section{Reducing horizontal vibrations}

The practical solutions to fulfill the dynamic conditions consist in increasing the moment of inertia of the deck relative to the vertical axle, Figure 8 . 


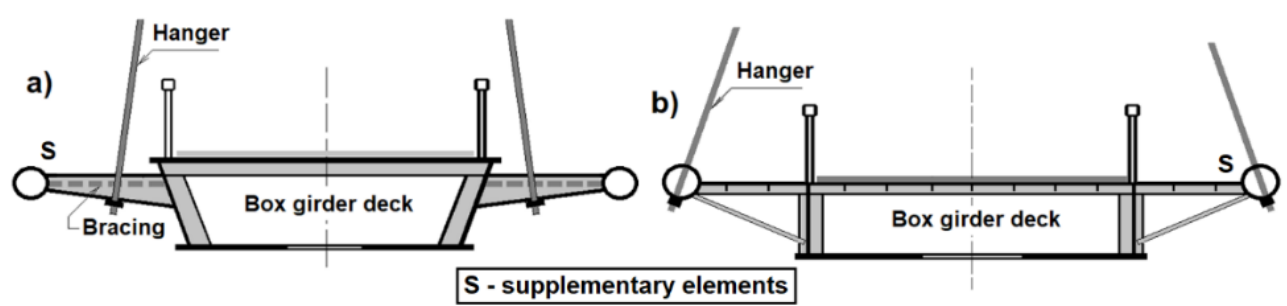

Fig. 8. Supplementary elements to increase the horizontal deck rigidity

Torsional vibrations

The improvement of the torsional vibration parameters can be obtained by increasing the torsional stiffness of the deck.

\section{Reducing the structure acceleration}

The reduction of the acceleration of the structure can be achieved by the following methods: increasing the mass of the construction by using heavy decks (concrete, asphalt); using materials with high damping properties; the use of manufactured dampers (devices including a parallel arched spring and a hydraulic shock absorber or other devices).

\subsection{Dampers}

In the case of a built-in footbridge, one can try to modify the natural vibration frequency by increasing the damping factor.

There are several types of devices that can be used and analyzed for footbridges in order to modify the dynamic parameters [1], [6], [7].

Viscous dampers

In the case of footbridges, the displacements are very small, so very sensitive devices need to be used to be effective. The devices, Figure 9, are interposed between the deck and the infrastructure or in the plane of the horizontal bracing.
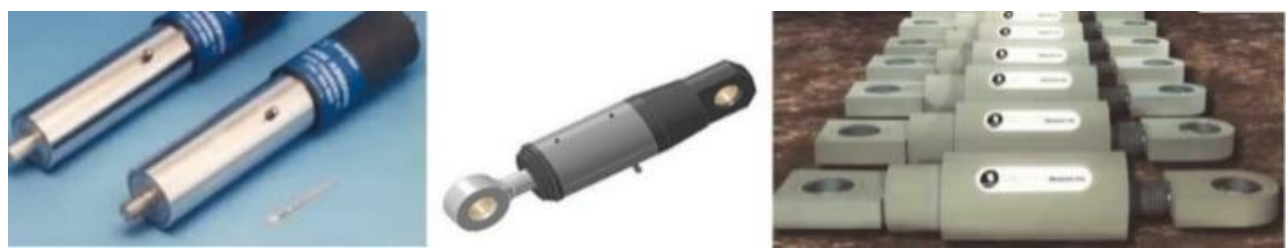

Fig. 9. Hydraulic dampers

TMD (Tuned mass dampers)

These devices are composed of a mass connected to the construction by a viscous spring and a damping system connected in parallel, Figure 10, and are very effective when the excitation frequency resonates with the frequency of the structure [7], [10]. 


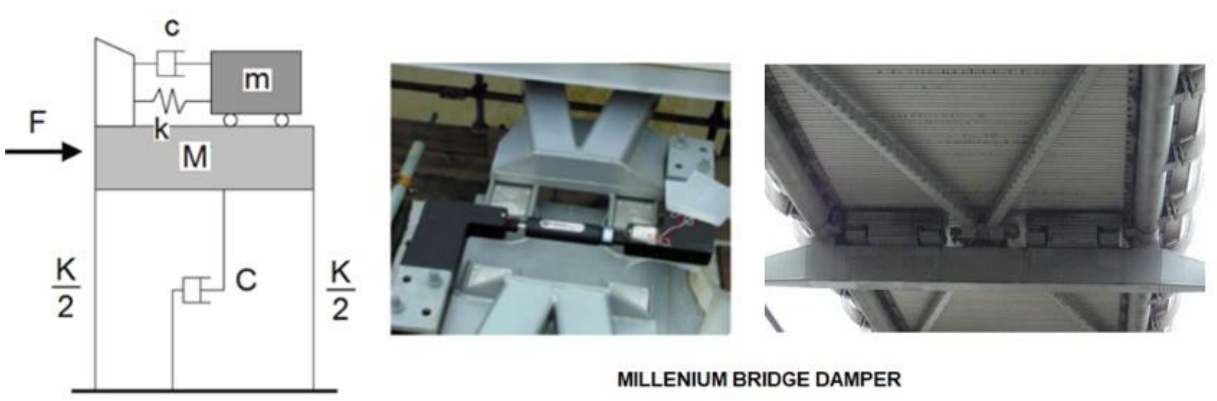

Fig. 10. TMD (Tuned mass dampers)

HTMD (Horizontal tuned mass damper)

The devices include a mass attached to the structure by a pendulum to produce vibrations that interfere with the horizontal natural frequencies of the structure.

The scheme of HTMD is shown in Figure 11, [6], [7].
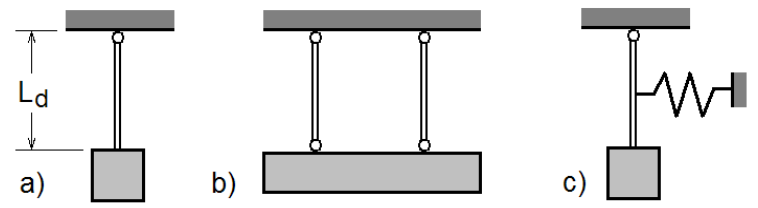

Fig. 11. HTMD devices

In papers [3], [4] and [5] several aspects regarding the dynamic response and the traffic comfort of some footbridges are presented.

\section{CONCLUSIONS AND DESIGN APPLICATIONS}

Pedestrian bridges are constructions that are part of the category Bridges, having the particularity that due to much lower loading in comparison to that of road and railway bridges, their decks are much slenderer, and can be included in the category of light and flexible structures.

The reduced rigidity in two planes - vertically and horizontally - makes the decks of the footbridges to be exposed to the phenomena of excess vibrations or even to get into resonance with direct consequence on the comfort of movement of the pedestrians or in extreme situations that of the collapse of the construction.

In the Feasibility study for a footbridge of $130 \mathrm{~m}$ span was necessary to increase the rigidity of the deck by adding two lateral stringers at a convenient distance from the deck axle, so the dynamic parameters fall within the limits required (see Figure 13).

The presentation of the work is detailed in the paper [3].

\section{REFERENCES}

[1] Moga P., Guţiu Şt., Moga C. (2020), Pasarele pietonale, Ed. U.T. PRESS, Cluj-Napoca [2] Moga P., Guţiu Şt., Moga C. (2016), Reabilitarea podurilor metalice, Ed. UT PRESS., Cluj-Napoca 
[3] Guțiu Şt. I., Moga C., Danciu A. (2019), Dynamic analysis of a footbridge structure on a central arch, Article No 5, Romanian Journal of Transport Infrastructure, Vol.8, No.2 58 [4] Moga P., Guţiu Şt. I., Anghel F., Moga C., Danciu A. (2016), Footbridge over the Somes River in Cluj-Napoca, Romania. The $9^{\text {th }}$ International Conference "Bridges in Danube Basin", 2016, published in "Procedia Engineering 156 (2016)" ELSEVIER

[5] Suciu M., Drăgan D., Nerişanu R. (2018), Relation between dynamic response and the traffic comfort of some footbridges on plate girders, The $18^{\text {th }}$ International Multidisciplinary Scientific Geoconference (SGEM 2018), Albena-Bulgaria, Conference Proceedings, Volume 18, Nano, Bio, Green and Space - Technologies for a Sustainable Future, Issue 6.3, pag. 681 688

[6] *** FIB Bulletin 32 (2005), Guidelines for the design of footbridges

[7] *** Sétra (2006), Technical guide. Footbridges. Paris

[8] *** SR EN 1990. Bazele calculului structurilor

[9] *** Proiecte realizate de XC PROJECT şi SC DRUMEX din Cluj-Napoca

$[10] * * *$ SITE-uri WEB de profil

\section{Note:}

Nerișanu Raluca - Technical University of Cluj-Napoca, 28 Memorandumului Street, 400114-ClujNapoca, Romania (corresponding author to provide phone: +40-728-671024; e-mail: Raluca.Nerisanu@cfdp.utcluj.ro).

Suciu Mircea - Technical University of Cluj-Napoca, 28 Memorandumului Street, 400114-Cluj-Napoca, Romania (e-mail: Mircea.Suciu@cfdp.utcluj.ro).

Drăgan Delia - Technical University of Cluj-Napoca, 28 Memorandumului Street, 400114-Cluj-Napoca, Romania (e-mail: Delia.Dragan@cfdp.utcluj.ro). 